\title{
Andi Selle dalam Pergolakan Bersenjata di Sulawesi Selatan (1950-1964)
}

\author{
Sainal Abidin \\ Guru Sejarah Sekolah Menengah Kejuruan Telkom Makassar \\ sainal.paccarita@gmail.com
}

\begin{abstract}
This paper describes the background, role and impact of the involvement of Andi Selle in the throes of armed in South Sulawesi. This research is a descriptive-analytic nature by using the historical method through phases of heuristics, critique, interpretation, and historiography. The involvement of Andi Selle in the throes of armed caused by internal conflict on TNI. Andi Selle was involved in a series of conflicts with several parties from the time of independence until the period before independence. The upheaval affects ethnic hatred caused by acts of violence and the monopoly of trade in the region committed soldiers, so that hurt the people of Mandar.
\end{abstract}

Keywords: Andi Selle, Armed Unrest, South Sulawesi.

\begin{abstract}
ABSTRAK
Tulisan ini menjelaskan tentang latar belakang, peranan dan dampak keterlibatan Andi Selle dalam pergolakan bersenjata di Sulawesi Selatan. Penelitian ini bersifat deskriptif analitis dengan menggunakan metode historis yang melalui tahapan heuristik, kritik, interpretasi, dan historiografi. Keterlibatan Andi Selle dalam pergolakan bersenjata disebabkan oleh konflik internal dalam tubuh TNI. Andi Selle terlibat dalam serangkaian konflik dengan beberapa pihak sejak masa sebelum kemerdekaan sampai periode kemerdekaan. Pergolakan tersebut berdampak pada kebencian etnis yang disebabkan oleh tindak kekerasan dan monopoli perdagangan di wilayah tersebut yang dilakukan prajuritnya, sehingga dianggap melukai hati rakyat Mandar.
\end{abstract}

Kata Kunci: Andi Selle, Pergolakan Bersenjata, Sulawesi Selatan.

\section{PENDAHULUAN}

Dinamika militer di Indonesia,

khususnya di Sulawesi Selatan memiliki sisi menarik dan penting untuk diamati.

Persoalan yang dimaksud

berkaitan dengan

kepentingan politik yang

memunculkan pertentangan dalam

internal TNI. Sebagai contoh, tindakan

pembangkangan yang dilakukan Andi
Selle bersama dengan pasukannya yang

merupakan salah satu bagian sejarah

yang menarik untuk diperhatikan. Andi

Selle merupakan salah satu tokoh yang

pernah tampil sebagai pejuang dalam

perang kemerdekaan. Namun, ia memilih

untuk keluar dari Tentara Nasional

Indonesia dan melakukan gerilya.

Berdasarkan uraian di atas, tulisan ini

berusaha untuk memaparkan beberapa 
bagian dari Andi Selle. Pertama, Andi Selle merupakan tokoh sentral di Pinrang dalam perang pada masa kemerdekaan.

Namun, dalam perkembangannnya terjadi penentangan terhadap pemerintahan yang sah, terutama pertentangannya dengan Kolonel Andi Muhammad Jusuf yang menggantikan Brigjen Andi Mattalatta, Panglima Kodam

XIV Hasanuddin. Kedua, dalam menjalankan tugasnya di daerah PolewaliMandar, Mamasa, Majene, dan Mamuju, Andi Selle banyak menimbulkan keresahan bagi masyarakat di daerah tersebut. Kondisi sosial yang terjadi dalam lingkup masyarakat Mandar, memiliki kaitan dengan monopoli dagang yang dijalankan. Ketiga, pada tahun 2003, beredar kabar di kalangan masyarakat, terutama di kalangan pendukungnya pada masa perang kemerdekaan dan masa gerilya, bahwa Andi Selle belum meninggal dan dia muncul kembali di tengah-tengah masyarakat pada masa itu. Keempat, penelitian-penelitian tentang Andi Selle belum banyak mendapat tempat dalam historiografi Indonesia.

\section{TINJAUAN PUSTAKA Teori Deprivasi Relatif}

Teori yang dianggap membantu dalam mengamati dan menganalisis fenomena perlawanan ataupun pemberontakan terhadap kondisi Negara adalah deprivasi relatif. Dalam teori-teori ilmu sosial, deprivasi relatif merupakan salah satu sudut pandang dalam menjelaskan terjadinya gerakan sosial.

Pada dasarnya, deprivasi relatif merupakan kondisi psikologis yang menguntungkan. Crosby menganggap bahwa deprivasi dapat diukur dari kondisi psikologis seperti marah, tidak puas, cemburu, putus asa, tidak bahagia dan lain-lain. Namun demikian, mereka memberikan catatan bahwa aspek psikologis tersebut berhubungan dengan deprivasi apabila berkaitan dengan keadilan (Faturochman, 1998: 7).

\section{Teori Konflik}

Pendekatan teoritis yang juga digunakan dalam tulisan ini adalah teori konflik. Konsep ini dianggap mampu membantu dalam melakukan penyelidikan terhadap pergolakan bersenjata yang melibatkan Andi Selle di Sulawesi Selatan. Sebagai makhluk individu, manusia tidak dapat lepas dari ketergantungan sejak lahir dan proses perkembangannya, hingga proses menuju kematian. Dalam dinamika kehidupan masyarakat, semua difokuskan pada pemenuhan harkat dan martabat dalam kehidupan sosial. Interaksi sosial yang dilakukan dalam kehidupan sehari-hari terkadang tidak sesuai dengan harapan, sehingga melahirkan konflik. Hal berbeda dikemukakan oleh Hebridge bahwa konflik menggambarkan solidaritas, dan para kritikus telah mempertukarkan satu komunitas, wilayah, atau bangsa dengan yang lain terhadap lahirnya kelas sosial. Salah satunya adalah menggunakan 
subkultur yang didefinisikan sebagai budaya yang tidak sepenuhnya dapat berdiri sendiri dan di dalam budaya yang lebih besar (Burke, 2015: 183).

\section{METODE PENELITIAN}

Tulisan ini merupakan penelitian sejarah dengan menggunakan pendekatan deskriptif analitis yang memberikan penekanan pada aspek kronologis terhadap peranan Andi Selle dalam pergolakan bersenjata di Sulawesi Selatan (1950-1964). Tulisan ini berusaha menggambarkan tentang peran Andi Selle dalam pergolakan bersenjata dilakukan di Sulawesi Selatan, khususnya di Kabupaten Pinrang.

Langkah pertama yang dilakukan dalam metode penelitian sejarah yaitu pengumpulan data (heuristik). Teknik pengumpulan data yang digunakan dalam tulisan ini adalah studi kepustakaan (library reseach). Pengumpulan data juga dilakukan dengan cara wawancara, dokumentasi dan pengkajian arsip.

Data yang diperoleh pada tahap heuristik masih diragukan validitasnya. Oleh karena itu, perlu dilakukan kritik sumber. Setiap sumber memiliki aspek eksteren dan interen. Aspek eksteren berkaitan dengan validitas sumber yang dibutuhkan, sedangkan aspek interennya berkaitan dengan apakah sumber sesuai dengan yang dibutuhkan atau tidak. Setelah data dikritik sumbernya, selanjutnya dilakukan interpretasi data. Dalam interpretasi, seorang peneliti bisa berbeda pendapat walaupun sumber datanya sama. Namun, yang terpenting adalah sumbernya jelas dan dapat dilakukan pengecekan kebenarannya.

Historiografi merupakan tahap akhir dari seluruh rangkaian metodologi penulisan sejarah. Pada tahap ini, realitas sejarah dipahami sesuai dengan semua yang terjadi, sehingga dapat mengisahkan tentang "Peranan Andi Selle dalam Pergolakan Bersenjata di Sulawesi Selatan: 1950-1964".

\section{PEMBAHASAN HASIL PENELITIAN Peranan Andi Selle dalam Organisasi Kelaskaran BPRI Suppa}

Kemerdekaan RI diproklamasikan di Jakarta oleh Soekarno Hatta tanggal 17 Agustus 1945 dan berita tersebut dengan cepat menyebar ke seluruh pelosok Tanah Air. Kegembiraan rakyat akan kemerdekaan itu diwujudkan dengan pengibaran bendera Merah Putih, sebagai bentuk kecintaan mereka terhadap Indonesia yang sekian lama dijajah oleh bangsa asing, terutama Belanda dan Jepang. Berita kemerdekaan juga tersebar di daerah Sulawesi Selatan hingga ke daerah-daerah pedalaman. Di daerah Parepare dihimpun kekuatan dari berbagai golongan, tak terkecuali keterlibatan para pemuda. Bendera Merah Putih dikibarkan di berbagai daerah, tidak terkecuali di daerah Suppa.

Dalam upaya mencegah gangguan susulan di pihak penjajah, Andi Selle mengerahkan seluruh rakyat di Alitta 
untuk berangkat menuju Suppa dalam rangka mempertahankan kemerdekaan RI. Wadah perjuangan pun dibentuk dengan nama Badan Pemberontak

Republik Indonesia (BPRI), sesuai dengan sikap mereka yang lebih tegas dalam melakukan pemberontakan terhadap penjajah Belanda (Pawiloy, 1989: 167).

BPRI Suppa dalam perkembangannya mengalami perubahan arti menjadi Badan Penunjang Republik Indonesia dan berpusat di Dolangan. BPRI Suppa dibentuk pada pertengahan September 1945 dan dipimpin langsung oleh Datu Suppa Andi Abdullah Bau Massepe dan sebagai wakilnya diserahkan kepada Andi Selle yang sebelumnya pernah menjadi Koordinator Pemuda Suppa. Dalam organisasi tersebut juga bergabung Andi Arsyad, La Bangnga, Ambo Siraje, Ambo Nonci, dan Pettana Rajeng (Kila, 1996). Meskipun demikian, yang bertindak sebagai pimpinan dalam BPRI Suppa lebih banyak dikendalikan oleh Andi Selle. Andi Abdullah Bau Massepe disibukkan dengan berbagai urusan kedatuan, sebab waktu itu dirinya menjabat sebagai Datu Suppa. Dalam Konferensi Paccekke pada tanggal 20-22 Januari 1947, Andi Selle diangkat sebagai Komandan Resimen I Divisi Hasanuddin dengan pangkat Letnan Kolonel (Kila, 1996: 64)

\section{Reorganisasi dan Konflik Internal di Pucuk Pimpinan Tentara}

Reorganisasi dan rasionalisasi tentara menjadi pemicu awal konflik di kalangan internal TNI. Di satu sisi, reorganisasi dan rasionalisasi dilakukan untuk meminimalisir keuangan negara di awal kemerdekaan, termasuk biaya hidup tentara. Kebijakan tersebut justru merugikan laskar pejuang kemerdekaan yang tidak diikutsertakan sebagai TNI. Persoalan rasionalisasi pada dasarnya berawal dengan adanya silang pendapat yang terjadi di Markas Besar Angkatan Darat di Jakarta tentang profil TNI.

Syarat menjadi anggota tentara nasional seperti yang diperdebatkan pada Mabes AD ialah bekas pejuang yang tidak buta huruf. Hal ini dianggap bertentangan dengan kondisi gerilyawan kemerdekaan Sulawesi termasuk pimpinan Kahar Muzakkar ataupun yang tergabung dibawah komando Andi Selle. (Paeni, 1992). Komandan Batalion 710 merasa dirugikan dengan kebijakan tersebut, sebab anak buahnya kebanyakan tidak pernah mengenyam pendidikan, sehingga memicu pembangkangan Andi Selle terhadap setiap perintah atasan demi mempertahankan anggota ketentaraan anak buahnya.

\section{Andi Selle dalam Batalion C.T.N (Corps Cadangan Nasional)}

Persoalan integrasi langsung KGSS (Komando Gerilya Sulawesi Selatan) menjadi bagian dari APRI (Angkatan Perang Republik Indonesia) tidak dapat dipenuhi oleh pemerintah. Kahar Muzakkar bersama dengan pengikutnya menunjukkan sikap tegas dalam proses 
perkembangan kaum gerilya tersebut. Awal Januari sampai pertengahan Agustus tahun 1951, Kahar Muzakkar membentuk komando penyelesaian yang diketuai oleh Saleh Syahban yang bertugas mendampingi Panglima TT VII Kawilarang dalam usaha melebur kaum gerilyawan KGSS ke dalam satuan TNI. Usaha komando penyelesaian yang tampak menonjol terjadi pada awal Maret 1951. Gerilyawan KGSS yang semula berstatus dirasionalisasikan menjadi satu resimen yang diresmikan menjadi Corps Cadangan Nasional (CTN), sambil menunggu saat diresmikan menjadi satuan tempur dalam jajaran TT VII yang peresmiannya dilaksanakan pada tanggal 17 Agustus 1951 di Makassar (Mattalioe, 1994: 156).

Kebijakan pemerintah pusat yang melantik Andi Selle dan Andi Sose sebagai anggota APRI (Angkatan Perang Republik Indonesia) tidak disetujui oleh Abdul Kahar Muzakkar yang tetap pada tuntutannya agar diresmikan sebagai anggota APRI di dalam satu Brigade Hasanuddin. Meskipun demikian, semua pasukan yang pernah dipimpin Abdul Kahar Muzakkar ada yang berhasil diresmikan menjadi bagian APRI setelah sebelumnya dilantik. Mantan pasukan CTN tersebut dulu berada dibawah Pimpinan Andi Selle.

Mantan pasukan ini dilantik karena peduli terhadap bangsa dan negara. Pelantikan tersebut dilakukan tanggal 17 Agustus 1945. Semua pasukan diberi pangkat Kopral dan ada pula yang diberi pangkat Sersan, sementara Andi Selle Mattola diberi pangkat Kapten dengan kedudukan sebagai Komandan Batalion 719 (Hadiwijoyo, 2013: 74). Awalnya batalion ini berkedudukan di Maros. Batalion ini berubah nama menjadi Batalion 710 yang berkedudukan di Polewali, serta membawahi beberapa daerah di bawahnya seperti Parepare, Pinrang, Polewali dan Majene (La Bora, wawancara tanggal 10 Mei 2016).

Keberhasilan pimpinan APRI meresmikan dan menarik Andi Selle beserta prajuritnya tidak terlepas dari peran serta nasehat Andi Mappanyukki dan Andi Pangeran Pettarani. Kedua orang inilah yang membujuk perwira tertinggi Markas Besar Tentara untuk segera melantik Andi Selle Mattola beserta para prajuritnya menjadi anggota APRI. Dengan kedudukan Raja Bone, Andi Mappanyukki di lingkungan Markas Besar Tentara sangat dihormati, maka perwira tinggi Markas Besar Tentara tidak dapat menolak bujukannya (Hadiwijoyo, 2013: 74).

Pasca diresmikannya batalion yang dipimpin Andi Selle, terjadi kerenggangan hubungan antara Andi Selle dengan Abdul Kahar Muzakkar. Kahar Muzakkar memperkuat pasukannya dan melakukan perlawanan terhadap pemerintah Indonesia, sedangkan Andi Selle bergabung dengan TNI (Natsir, 2004: 207). 


\section{Andi Selle sebagai Komandan Korem IV Mappesonae}

Andi Selle bersama pasukan 710 yang dipimpinnya telah memberikan sumbangsih yang cukup besar dalam perjuangan kemerdekaan bangsa

Indonesia, terutama di daerah Sulawesi Selatan, seperti Pinrang, Pare-pare, Mandardan dan sekitarnya. Namun, ketika bertugas di Polewali Mandar, Andi Selle dianggap memberikan pengaruh negatif yang ditimbulkan oleh para pengikutnya. Pasukan Andi Selle dianggap sebagai pengacau oleh sebagian masyarakat, termasuk oleh mantan atasannya, yakni Abdul Kahar Muzakkar. (Arsip Pemerintah Prov. Sulawesi Selatan).

\section{Andi Selle dan Negara Federasi}

Pada awal tahun 1950, Andi Selle bersama pasukannya setelah berjuang di dalam wilayah pusat Pemerintahan Indonesia (Jawa), kembali ke Sulawesi Selatan atas permintaan Kahar Muzakkar. Hal ini berhubungan dengan kondisi politik yang semakin kacau, sehingga mengharuskan semua putra terbaik daerah kembali secara bersama-sama untuk berbenah. Puncak dari pergolakan yang terjadi di Negara Indonesia Timur pasca Konferensi Meja Bundar (KMM) adalah pemberontakan yang lebih dikenal dengan Peristiwa Andi Aziz (Rukmy, 2006: 16). Ketimpangan pembangunan di antara di Jawa dengan daerah lainnya, membuat Andi Selle kecewa. Selain itu, ia tidak suka dengan kedatangan orangorang Jawa ke Sulawesi apalagi menjadi pemimpin di daerah ini (Tangke, dkk 2011: 38-39). Temasuk dengan kehadiran pasukan APRIS dari kesatuan Siliwangi di Sulawesi (Ratmanto, 2012: 148).

\section{Konspirasi Andi Selle dengan Gerakan DI/TII}

Ditolaknya integrasi langsung Komando Gerilyawan Sulawesi Selatan (KGSS) ke dalam angkatan perang Republik Indonesia Serikat (APRIS) menjadi alasan kelompok Kahar Muzakar meninggalkan semua tanda kemiliterannya untuk kemudian masuk hutan bersama pengikutnya. Melihat sikap tersebut, PM Nasir berusaha menempuh cara-cara damai guna menyelesaikan masalah KGSS.

Pemerintah dan KGSS akhirnya mencapai kesepakatan. Kahar Muzakar sendiri akan diberi pangkat acting Letnan Kolonel.

Namun, dalam acara pelantikannya pada Agustus 1951, ia memilih melarikan diri dan kembali masuk hutan. Pada tanggal 20 Januari 1952, Kahar Muzakar menyatakan menjadi bagian negara Islam Indonesia di bawah S.M. Kartosuwiryo (Ratmanto, 2012: 160). Penggabungan batalion Bau Massepe pimpinan Andi Selle ke dalam tentara sebagai Batalion 719 pada tanggal 7 Agustus 1951 hanyalah memperbesar pertentangan antara Abdul Kahar Muzakkar dan tentara dalam periode setelahnya (Maesaroh, 2007: 23).

Aktivitas perdagangan memiliki arti penting dalam pemberontakan ataupun 
pergolakan yang terjadi di Sulawesi Selatan, termasuk DI/TII dan Batalion 710 di bawah Pimpinan Andi Selle. Proses perdagangan dilakukan dengan cara barter baju-baju khusus perang, senjatasenjata ringan dan berat, serta peluru sebagaimana yang dilakukan Andi Selle Mattola (Hadiwijoyo, 2013: 57). Olehnya, Andi Selle dipandang sebagai sumber utama bagi suplai DI/TII di Sulawesi Selatan (Harvey, 1989: 326).

\section{Monopoli Perdagangan Kopra}

Dalam rangka menjamin kebutuhan logistik, termasuk persenjataan anak buahnya, Andi Selle yang memiliki kekuasaan di daerah Suppa-Pinrang meliputi lima kabupaten, telah melakukan usaha monopoli perdagangan kopra di wilayah tersebut. Komoditi dagang ini diangkut ke luar daerah seperti

Tawao dan Singapura, kemudian ditukar/dibarter dengan senjata. Hal ini dianggap lebih menguntungkan pihak mereka dibandingkan dengan cara menjual langsung kepada konsumen. Walaupun harus dijual, seluruh hasil penjualan dibelikan kembali senjata guna perjuangan resimen Andi Selle di Sulawesi Selatan. Kelancaran arus perdagangan yang dilakukan Andi Selle karena didukung oleh sarana kapal yang dimiliki secara pribadi oleh beliau (Kila, 1996: 65).

Keberhasilan Andi Selle menguasai dan memonopoli perdagangan kopra di wilayah Mandar tidak terlepas dari peranan Anak buahnya. Konco-konco
Andi Selle juga berusaha menjalankan peranannya dalam perdagangan dengan cara menandatangani izin Smoukel Kopra keluar Sulawesi. Hal tersebut merupakan perbuatan korupsi terhadap tuannya sendiri yaitu pemerintah Soekarno-Hatta. Bukan hanya kosupsi surat izin keluar, di beberapa tempat secara diktator absolut anarkis juga memerkosa penghidupan pedagang-pedagang kopra kecil di Mandar (Arsip Pemerintah Provinsi

Sulawesi Selatan).

Para petani di Majene sering dipaksa untuk menjual buah kelapanya secara langsung kepada anggota TBO. Pasukan Batalyon 710 pimpinan Andi Selle juga mengambil alih semua perkebunan Belanda yang tersebar di daerah Mandar (Polmas, Majene, dan Mamuju). Intensitas berdagang Batalyon 710 terus meningkat, bukan hanya mengincar kopra dari petani, tetapi juga melebar ke perkebunanperkebunan peninggalan Belanda tanpa melibatkan pihak lain (Asba, 2007: 227).

Hasil perdagangan yang dilakukan Andi Selle beserta para pengikutnya telah memberikan kesejahteraan bagi dirinya beserta keluarganya. Menurut H. Rosihan Anwar (dalam Kila, 1995: 65) hasil perdagangan yang dimonopoli oleh Andi Selle di lima wilayah kabupaten guna menunjang kelancaran perjuangannya, telah membawa Andi Selle menjadi orang kaya. Tidak hanya harta milik Andi Selle, beberapa harta benda dari keluarga dan kerabat Andi Selle juga dicurigai sebagai 
miliknya, seperti rumah dan isinya milik Andi Achmad (penjaga empang Andi Selle), di Langga yang diusut pada tanggal 30 Mei 1964 (Arsip Pemda Pinrang).

\section{Perundingan Damai Berujung Maut}

Berbagai upaya ditempuh oleh pemerintah, seperti upaya damai yang dilakukan pihak Kodam VII Wirabuana di bawah komando Jenderal M. Jusuf yang meminta Andi Selle untuk meninggalkan posnya yang bertempat di Polewali Mandar. Akan tetapi, Andi Selle tidak menghiraukan perintah atasannya itu. Panglima Kodam VII Wirabuana kemudian menyusun strategi untuk melakukan negosiasi dan diplomasi atas penyelesaian masalah tersebut. Atas usul dari Jenderal M. Jusuf, disepakatilah secara bersama untuk melakukan perundingan yang berlokasi di Kabupaten Pinrang.

Proses perundingan yang dilakukan pada 5 April 1964 melibatkan banyak orang di dalamnya. Masing-masing telah menyiapkan dirinya dengan segala kemungkinan yang terjadi, baik dari pihak Andi Selle maupun pihak Panglima M. Jusuf. Sebelum menuju ke lokasi perundingan, Pangdam Hasanuddin Kolonel M. Jusuf bersama dengan rombongan berkunjung ke Markas Yon Kujang di Enrekang. Dalam kesempatan tersebut, ikut serta beberapa orang kepercayaan Kolonel Jusuf, yaitu Letkol Suharsono (Asisten Operasi Koandait), Kolonel CPM Sugiri (Kepala Polisi Militer daerah XIV), dan Kombes Drs.
Mardjaman. Kedatangan Pangdam di Kab. Enrekang bermaksud untuk memberikan perintah kepada Dan Yon Kujang Mayor Himawan Soesanto agar mempersiapkan diri dan satu kompi pasukan terbaiknya untuk mengawal Kolonel M. Jusuf dalam pertemuannya dengan Andi Selle di Pinrang (Ratmanto, 2012: 168).

Setelah semuanya siap, maka dilakukanlah perundingan di sebuah tempat yang berada di pinggiran Kota Pinrang, tepatnya di Desa Leppangan di sebuah Gedung Bulog. Sebagaimana dilukiskan pelaku sejarah Andi Naga, mantan ajudan pribadi Andi Selle, bahwa ketika itu mereka berangkat dari Polewali sekitar jam 07.00 bersama dengan beberapa orang yang ikut di dalam sebuah mobil Jip dan sebelum tiba di lokasi perundingan, rombongan sempat singgah membeli rokok untuk dibawa pada saat perundingan yang akan berlangsung (Andi Naga, Wawancara 4 Mei 2016).

Jarak dari Leppangang ke kediaman Bupati H. Andi Makkulau di Kota Pindrang kurang lebih $8 \mathrm{~km}$. Dalam perjalanan itulah terjadi peristiwa Pinrang tanggal 5 April 1964. Kendaraan yang ditumpangi oleh Pangdam XIV/Hasanudin M.Yusuf dan Andi Selle telah sampai ke Kota Pinrang dan menuju ke Rumah Bupati. Seharusnya kendaraan itu berbelok ke kanan kediaman yang dituju, tetapi ternyata kendaraan yang ditumpangi tersebut tetap terus dan seakan-akan mau ke Parepare untuk kemudian ke Makassar. Kontak senjata tidak dapat dihindari 
dalam insiden tersebut yang mengakibatkan adanya korban dari kedua belah pihak. Meskipun pertempuran tersebut berlangsung singkat, insiden tersebut memakan banyak korban, baik yang luka-luka maupun yang tewas dalam kejadian tersebut. Beberapa korban tewas diantaranya, Peltu Daud Supriyanto, Praka Adang B, dan Kolonel Sugiri.

Adapun Kombes Polisi Mardjaman, Supir Langnga, dan sejumlah prajurit kujang luka-luka. Sementara itu, Andi Selle beserta ratusan pasukannya melarikan diri dan meninggalkan rekan-rekan mereka yang tergeletak tewas (Ratmanto, 2012: 173).

Pada saat itu Andi Selle dikawal oleh masyarakat menuju Lerang-lerang. Di daerah itu, Andi Selle beserta pasukannya dijemput oleh dua tokoh masyarakat, yakni P. Marrung dan H. Wasina. Berselang beberapa waktu, empat orang anak buahnya datang menyusul, dua orang anak buahnya mengalami luka-luka akibat terjadinya tembak-menembak (P. Amba, Wawancara pada tangga 5 Mei 2016).

Setelah mendapat perawatan secara sederhana, Andi Selle meminta supaya disiapkan kuda yang ingin digunakan untuk menyeberang dari tempat itu menuju daerah Suppa. Namun, sebelum meninggalkan tempat itu, Andi Selle sempat mengatakan kepada pengikutnya, “iye kejadiangnge gara-gara sipa'na La Napi, aja mupasitaka narangnga mate', masolang maneng tauwe nataro, masolang manengngi rakyat'e". (Peristiwa ini disebabkan oleh perbuatan Andi Napi, jangan kau pertemukan saya dengannya sampai akhir hayatku, semua orang jadi korban akibat perbuatannya) (P. Amba, wawancara 5 Mei 2016).

Andi Selle sebagai pimpinan juga meminta agar anak buahnya dirawat dan dilindungi dari pasukan TNI. Berselang beberapa menit, Andi Selle meminta disiapkan kuda untuk digunakan menuju Corawali dan dijemput oleh penduduk setempat, kemudian melanjutkan perjalananya menuju Alitta tepatnya di Dusun Bottae yang dijemput oleh Ambo Bunga dan La Salama (Keduanya merupakan pasukan Andi Selle) dan sempat tinggal selama dua malam di suatu tempat yang jauh dari pemukiman. Pada saat itu, ia dirawat dan diberi makan oleh La Cokke (H. Kile, Wawancara, tanggal 6 Mei 2016).

Atas bantuan La Tanjong, Andi Selle bersama rombongan melanjutkan perjalanan menuju Suppa, tepatnya di daerah Parengki. Dalam rombongan tersebut Mayor Tallara, Andi Naga, La Cokke dan beberapa orang lainnya menuju Suppa dan singgah dirumah $P$. Cape'. (H. Kile, wawancara, tanggal 6 Mei 2016). Setelah sampai di Parengki Andi Selle bersama dengan rombongan ingin melanjutkan perjalanan ke daerah Polewali. Kemudian dari Parengki mereka melewati lautan menggunakan perahu menuju Bulu (Gunung) Sirasa melewati 
Bulu (Gunung) pakoro'. (La Samaila, Wawancara, 5 Mei 2016).

Berselang beberapa waktu setelah terjadinya pergolakan yang terjadi 5 April 1964, Andi Selle beserta pasukan setianya semakin terdesak hingga mereka harus bergerilya di hutan. Hampir setiap gunung yang terdapat diantara perbatasan Pinrang dan Polewali Mandar, termasuk Gunung Pakoro dan gunung Sirasa pernah dijadikan sebagai tempat persembunyian Andi Selle (wawancara P. Amba Tanggal 5 Mei 2016). Tempat itu dijadikan sebagai tempat berdiam semasa pelarian dan perburuan yang dilakukan oleh Kodam XIV/Hasanuddin dalam melakukan Operasi Tumpas.

\section{Dampak dari Pergolakan Bersenjata}

Keberlangsungan pergolakan bersenjata di Sulawesi Selatan yang melibatkan Andi Selle telah menimbulkan berbagai akibat. Baik dari segi politikmiliter, sosial-ekonomi, bahkan juga moral. Setelah diadakan operasi penumpasan terhadap pasukan Andi Selle yang tergabung dalam batalion $710 \mathrm{di}$ daerah Mandar, terdengar berita-berita positif tentang penghancuran kekuatankekuatan pensiunan Letkol Andi Selle Mattola cs oleh pemerintah pusat. Dengan demikian, masyarakat tidak lagi dihantui ketakutan dan tekanan psikologis. Aktivitas masyarakat pun berjalan normal kembali (Arsip Pribadi Andi Rahman Tamma).

Pembangunan di daerah Polewali Mandar dan wilayah sekitarnya pasca pemberontakan Andi Selle berjalan dengan normal. Meskipun demikian, masyarakat Mandar mengalami trauma akibat adanya pergolakan yang terjadi di daerahnya. Andi Selle Mattola yang ketika itu menjabat sebagai Komandan Korem IV Mappesonae, menyerukan kepada masyarakat Mandar yang pergi dengan terpaksa dari kampung halamannya akibat gangguan keamanan di masa lampau agar kembali untuk membangun daerah ini (Koran Tanah Air terbit 17 Agustus 1960). Selama 10 Tahun (19541964) terjadi proses kebencian etnis terhadap sikap penguasaan yang dilakukan oleh Andi Selle. Mereka dianggap sebagai pemeras rakyat Mandar melalui perdagangan beras dan kopra yang merupakan hasil utama daerah Mandar (Gonggong 2004:337).

\section{PENUTUP}

Pergolakan bersenjata yang melibatkan Andi Selle pada dasarnya dilatarbelakangi beberapa faktor. Pertama, pengangkatan Andi Muhammad Yusuf sebagai panglima Kodam XIV Hasanuddin menggantikan Andi Mattalatta. A. Muhammad Yusuf dianggap bukan perwira yang pantas menggantikan Andi Mattalatta, sebab Andi Selle lebih senior dari pada Andi Muhammad Yusuf. Kedua, pembangunan yang tidak merata antara Jawa dan Sulawesi merupakan alasan dilakukannya penentangan terhadap pemerintahan yang sah. 
Pergolakan bersenjata yang melibatkan Andi Selle dengan Andi Muhammad Jusuf terjadi pada 5 April 1964. Peristiwa tersebut disebabkan adanya penolakan Andi Selle terhadap Andi Muhammad Jusuf sebagai Panglima Kodam, serta perbedaan pendapat keduanya mengenai gerombolan DI/TII. Dampak yang ditimbulkan dari pergolakan bersenjata yang melibatkan Andi Selle ialah masyarakat Mandar mengalami tekanan psikologis yang berjalan dalam waktu yang cukup lama, sehingga mengakibatkan adanya kebencian etnis dan pembangunan daerah yang tidak berjalan dengan baik.

\section{REFERENSI}

Badan Arsip dan Perpustakaan Daerah Provinsi Sulawesi Selatan, Arsip Pribadi Andi Rahman Tamma (19501965) No. Reg: 486.

Badan Arsip dan Perpustakaan Daerah Provinsi Sulawesi Selatan, Arsip Pemda Tk II Pinrang (1947-1985). No. Reg: 1229.

Badan Arsip dan Perpustakaan Daerah Provinsi Sulawesi Selatan, Arsip Pemda prov. Sulawesi Selatan (19461960). No. Reg: 480.

Asba, A. R. 2007. Kopra Makassar Perebutan Pusat dan Daerah; Kajian Sejarah Ekonomi Politik Regional di Indonesia. Jakarta, Yayasan Obor Indonesia.

Burke, P. 2015. Sejarah dan Teori Sosial. Jakarta. Yayasan Pustaka Obor Indonesia

Faturochman. 1998. Deprivasi Relatif: Rasa Keadilan dan Kondisi Psikologis Buruh Pabrik. Universitas Gadjah Mada. Jurnal.
Gonggong, A. 1990. Abdul Qahhar Mudzakkar dan Gerakan DI/TII di Sulawesi Selatan. Jakarta. Universitas Indonesia, Disertasi

.1992. Abdul Qahhar Mudzakkar dari Patriot Hingga Pemberontak. Jakarta. PT Gramedia Widiasarana Indonesia

Hadiwijoyo, S. 2013. Kahar Muzakkar dan Kartosuwiryo. Jogjakarta. Palapa.

Harvey, B. S. 1989. Pemberontakan Kahar Muzakkar: dari Tradisi ke DI/TII. Jakarta. Pustaka Utama Grafiti.

Kila, S. 1996. Kelaskaran "45" Di Sulawesi Selatan: BBPRI Suppa dan BP. Gangawa. Ujung Pandang. Depertemen Pendidikan dan Kebudayaan Direktorat Jenderal Kebudayaan, Balai Kajian Sejarah dan Nilai Tradisional.

1997. Sejarah Perjuangan Kemerdekaan Republik Indonesia Tahun 1945-1949 di Pinrang. Ujung Pandang. Depertemen Pendidikan dan Kebudayaan Direktorat Jenderal Kebudayaan, Balai Kajian Sejarah dan Nilai Tradisional.

Maesaroh, S. 2007. Abdul Qahhar Muzakkar Sang Patriot Pejuang Islam. Tanggerang. Yayasan Al-Abrar.

Mattalioe, M. B. 1994. Pemberontakan Meniti Jalur Kanan. Jakarta, PT. Gramedia Widiasarana Indonesia.

Natsir, M. 2004. Darul Islam/Tentara Islam Indonesia di Massenrengpulu: Studi tentang Integrasi Gerilya ke dalam Negara Kesatuan Republik Indonesia. Tesis. Program Pasca Sarjana Universitas Negeri Makassar.

Paeni, M. 1992. Rasionalisasi Tentara, Satu Dilema Pasca Kemerdekaan Indonesia Timur. Makalah, disampaikan pada tanggal 16 Juli 1992

Ratmanto, A. 2012. Pasukan Siliwangi: Loyalitas, Patriotisme dan Heroisme. Yogyakarta: Mata Padi Pressindo. 
Rukmy. 2006. Apa dan Siapa RMS. Jakarta. Timpani Publising.

Harian Tanah Air. Tanggal terbit 17 Agustus 1960. Kodam XIV Sulselra, Korem Hn IV Mapesonae.

Wawancara dengan Andi Naga Pettana Rajeng (Pensiunan TNI/Mantan Ajudan Pribadi Andi Selle) tanggal 4 Mei 2016.

Wawancara dengan La Samailah (Pensiunan Tentara) tanggal 4 Mei 2016.

Wawancara dengan P. Amba (Petani) tanggal 5 Mei 2016.

Wawancara dengan La Bora (Pensiunan Tentara/Bekas Anggota DI/TII) tanggal 10 Mei 2016. 